\title{
Relationship between Oversulfation and Conformation of Low and High Molecular Weight Fucoidans and Evaluation of Their in Vitro Anticancer Activity
}

\author{
Myoung Lae Cho ${ }^{1}$, Boo-Yong Lee ${ }^{2, *}$ and SangGuan You ${ }^{1, *}$
}

1 Department of Marine Food Science and Technology, Gangneung-Wonju National University, Gangneung, Gangwon 210702, Korea; E-Mail: meanglae@naver.com (M.L.C.)

2

Department of Food Science and Biotechnology, CHA University, Seongnam, Kyunggi 463836, Korea

* Authors to whom correspondence should be addressed; E-Mail: umyousg@gwnu.ac.kr (S.G.Y.); bylee@cha.ac.kr (B.-Y.L.); Tel.: +82-33-640-2853(S.G.Y.); +82-31-725-8371 (B.-Y.L.); Fax: +8233-640-2850 (S.G.Y.); +82-31-725-8350 (B.-Y.L.).

Received: 30 November 2010; in revised form: 24 December 2010 / Accepted: 28 December 2010 / Published: 30 December 2010

\begin{abstract}
Low and high molecular weight fucoidans $\left(\mathrm{F}_{5-30 \mathrm{~K}}\right.$ and $\left.\mathrm{F}_{>30 \mathrm{~K}}\right)$ were chemically modified through the addition of sulfate groups, and the effect of oversulfation on the in vitro anticancer activity was investigated. After the addition of sulfate groups, a considerable increase of 35.5 to $56.8 \%$ was observed in the sulfate content of the $\mathrm{F}_{5-30 \mathrm{~K}}$ fraction, while the sulfate content of the $\mathrm{F}_{>30 \mathrm{~K}}$ fraction increased to a lesser extent (from 31.7 to $41.2 \%$ ). Significant differences in anticancer activity were observed between the oversulfated $F_{5-30 \mathrm{~K}}$ and $\mathrm{F}_{>30 \mathrm{~K}}$ fractions, with activities of $37.3-68.0 \%$ and $20.6-35.8 \%$, respectively. This variation in the anticancer activity of oversulfated fucoidan derivatives was likely due to differences in their sulfate content. The results suggest that the molecular conformation of these molecules is closely related to the extent of sulfation in the fucan backbones and that the sulfates are preferably substituted when the fucoidan polymers are in a loose molecular conformation.
\end{abstract}

Keywords: fucoidans; oversulfation; molecular conformation; anticancer activity; Undaria pinnatifida 


\section{Introduction}

Fucoidan, a sulfated-fucan, is commonly found in brown seaweed [1] and marine invertebrates, particularly in echinoderms such as sea cucumbers and sea urchins [2]. Fucoidans have been extensively studied due to their diverse anticoagulant, antiviral and anticancer properties. These biological activities have been reported to be closely related to their molecular weight and sulfate content. In a study of fucoidan hydrolysates, partially hydrolyzed fucoidans $\left(\mathrm{M}_{\mathrm{w}}=490 \mathrm{kDa}\right)$ showed significantly improved anticancer activity compared to the native polymers $\left(\mathrm{M}_{\mathrm{w}}=5,100 \mathrm{kDa}\right)$, and the effect was mostly seen when fucoidans were hydrolyzed under mild conditions [3]. The mechanisms whereby lower molecular weight fucoidans have greater anticancer activities appear to be very complex and are not clearly understood. Sulfate content was first identified as a possible factor by Soeda et al. [4], who reported that fucoidan derivatives with various sulfate contents stimulate tissue plasminogen activator (t-PA)-induced plasma clot lysis and prevent the formation of fibrin polymers, and that such activities increase proportionally with the degree of sulfation. It was also suggested that oversulfated fucoidans possess higher anti-angiogenic activity than native fucoidans, and thus more effectively inhibit the growth of tumor cells by suppressing angiogenesis [5]. Partially desulfated fucoidans with sulfate contents of less than $20 \%$, on the other hand, show drastic decreases in both anticoagulant and anticancer activities [6]. These studies suggest that the biological activities of fucoidans are significantly influenced by sulfate content and could be improved by the modification of this feature. Numerous studies have investigated the biological activities of oversulfated fucoidans. However, the extent of sulfation following the oversulfation reaction has been variable, ranging from 48 to $56 \%[5,7,8]$. Despite these differences, there have been no reports of the factors affecting the extent of sulfation of fucoidans.

In a preliminary study, we extracted a fucoidan from the sporophyll of Undaria pinnatifida, hydrolyzed it under a mild acidic conditions and subsequently fractionated it using an ultrafiltration system equipped with 30 and $5 \mathrm{kDa}$ membranes, which resulted in the production of three fucoidan fractions: $F_{>30 \mathrm{~K}}, F_{5-30 \mathrm{~K}}$ and $\mathrm{F}_{<5 \mathrm{~K}}$. The major constituents of the $\mathrm{F}_{>30 \mathrm{~K}}$ and $\mathrm{F}_{5-30 \mathrm{~K}}$ fractions were carbohydrate (58.2-61.3\%) and sulfate (31.7-35.5\%) with a small amount of protein, while that of the $\mathrm{F}_{<5 \mathrm{~K}}$ fraction was mostly sulfate and ash with little carbohydrate $(15.5 \%)$. When the in vitro anticancer activities of these fractions were studied, the $\mathrm{F}_{5-30 \mathrm{~K}}$ fraction exhibited the most potent anticancer activity. In the current study, the $\mathrm{F}_{>30 \mathrm{~K}}$ and $\mathrm{F}_{5-30 \mathrm{~K}}$ fractions (having molecular weights of 262 and $5.6 \mathrm{kDa}$, respectively), were chemically modified by the addition of sulfate groups, and the effect of the molecular conformation on the extent of sulfation and the in vitro anticancer activity of oversulfated fucoidan derivatives was investigated.

\section{Results and Discussion}

The sulfate contents of two native fucoidan fractions and their oversulfated derivatives are shown in Table 1. After the addition of sulfate groups, there was a considerable increase in the sulfate content of the $\mathrm{F}_{5-30 \mathrm{~K}}$ fraction from $35.5 \%$ to $56.8 \%$. In contrast, the sulfate content of the $\mathrm{F}_{>30 \mathrm{~K}}$ fraction only increased from $31.7 \%$ to $41.2 \%$. 
Table 1. The sulfate contents of native and oversulfated fucoidans.

\begin{tabular}{ccc}
\hline Sample & $\mathbf{F}_{\mathbf{5 - 3 0 k}} \mathbf{( \% )}$ & $\mathbf{F}_{>\mathbf{3 0 k}} \mathbf{( \% )}$ \\
\hline Native fucoidan & $35.5 \pm 1.9$ & $31.7 \pm 2.2$ \\
Oversulfated fucoidan & $56.8 \pm 2.3$ & $41.2 \pm 0.9$ \\
\hline
\end{tabular}

These changes in sulfate content were also supported by evidence from the IR spectra (Figure 1). The sulfate peaks around 820 and $840 \mathrm{~cm}^{-1}$ are related to the equatorial $\mathrm{C}-2$ and axial $\mathrm{C}-4$ positions, respectively [9]. As shown in Figure 1, the native fucoidans of the $F_{5-30 \mathrm{~K}}$ and $\mathrm{F}_{>30 \mathrm{~K}}$ fractions exhibited a strong peak around $840 \mathrm{~cm}^{-1}$, indicating that the sulfates were largely substituted at the C-4 position. In contrast, the oversulfated derivatives of $\mathrm{F}_{5-30 \mathrm{~K}}$ and $\mathrm{F}_{>30 \mathrm{~K}}$ fractions displayed a major peak at $840 \mathrm{~cm}^{-1}$ with a shoulder at $820 \mathrm{~cm}^{-1}$, indicating the 2,4 disubstitution of sulfate groups. These results are consistent with those of Qiu et al. [8], who also reported that sulfation led to the appearance of a shoulder at $820 \mathrm{~cm}^{-1}$ accompanied by a main peak at $840 \mathrm{~cm}^{-1}$ in the IR spectra, suggesting the occurrence of the 2,4 disulfation. Sulfation at the C-2 and/or C-4 positions is most likely to occur if the backbones of the fucoidans extracted in this study were connected by 1,3-glycosidic bonds.

Figure 1. FT-IR spectrums of (a) native and (b) oversulfated fucoidans. The fucoidans were scanned between 500 and $1,200 \mathrm{~cm}^{-1}$.

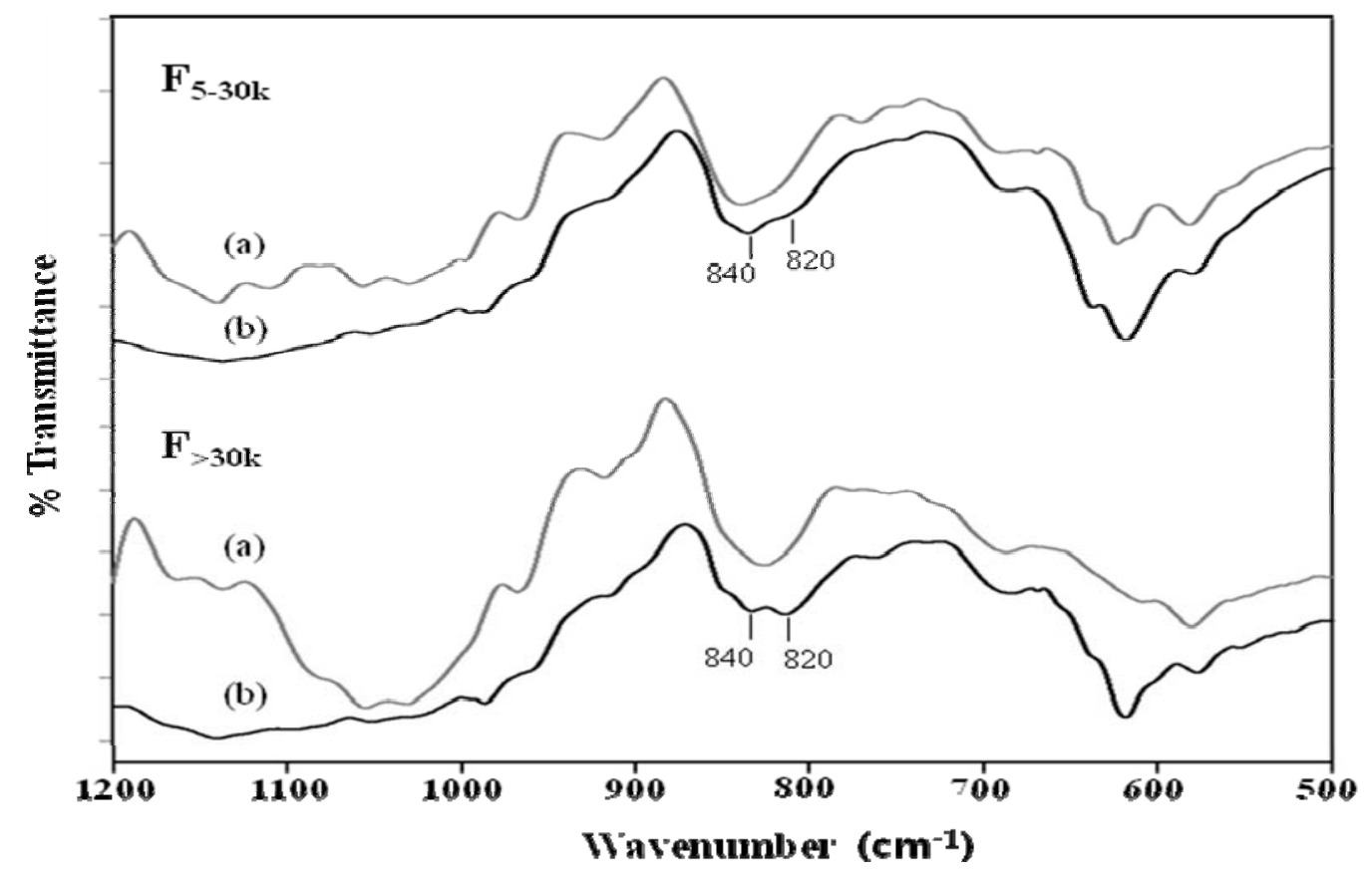

The anticancer activity of native and oversulfated fucoidans, expressed as a percentage of the growth inhibition of the cancer cell line AGS, is shown in Figure 2. At concentrations from 0.2 to $0.8 \mathrm{mg} / \mathrm{mL}$, the native $\mathrm{F}_{5-30 \mathrm{~K}}$ fraction inhibited the growth of cancer cells in a strong dose-dependent manner and had anticancer activities in the range of $19.2 \%$ to $57.5 \%$. In contrast, the native $\mathrm{F}_{>30 \mathrm{~K}}$ fractions displayed a relatively weak dose-dependent inhibition and had anticancer activities in the range of $18.0 \%$ to $28.5 \%$. When oversulfated, the fucoidan derivatives significantly increased the inhibition of cell growth. Significant differences were observed in the anticancer activities of the oversulfated $\mathrm{F}_{5-30 \mathrm{~K}}$ and $\mathrm{F}_{>30 \mathrm{~K}}$ fractions, with the $\mathrm{F}_{5-30 \mathrm{~K}}$ fraction inhibiting growth by $37.3 \%$ to $68.0 \%$ 
and the $\mathrm{F}_{>30 \mathrm{~K}}$ fraction by $20.6 \%$ to $35.8 \%$, depending on the fucoidan concentration. This considerable variation in the anticancer activity of the oversulfated fucoidan derivatives is likely due to differences in their sulfate content. This finding is supported by the results of Haroun-Bouhedja et al. [6], who showed that the antiproliferative activity of CCL39 cells proportionally increases with sulfate content and that fucoidans containing more than $40 \%$ sulfates inhibit the growth of CCL 39 cells by over $90 \%$. Although the underlying mechanism was not completely understood, the authors suggested that increased negative charges caused by oversulfation facilitate the formation of fucoidan-protein complexes involved in the cell proliferation, resulting in a greater suppression of cell growth.

Figure 2. Anticancer activity of native and oversulfated fucoidans against the human stomach cancer cell line AGS. (a) $\mathrm{F}_{5-30 \mathrm{~K}}$ fraction of native and oversulfated fucoidans and (b) $\mathrm{F}_{>30 \mathrm{~K}}$ fraction of native and oversulfated fucoidans.
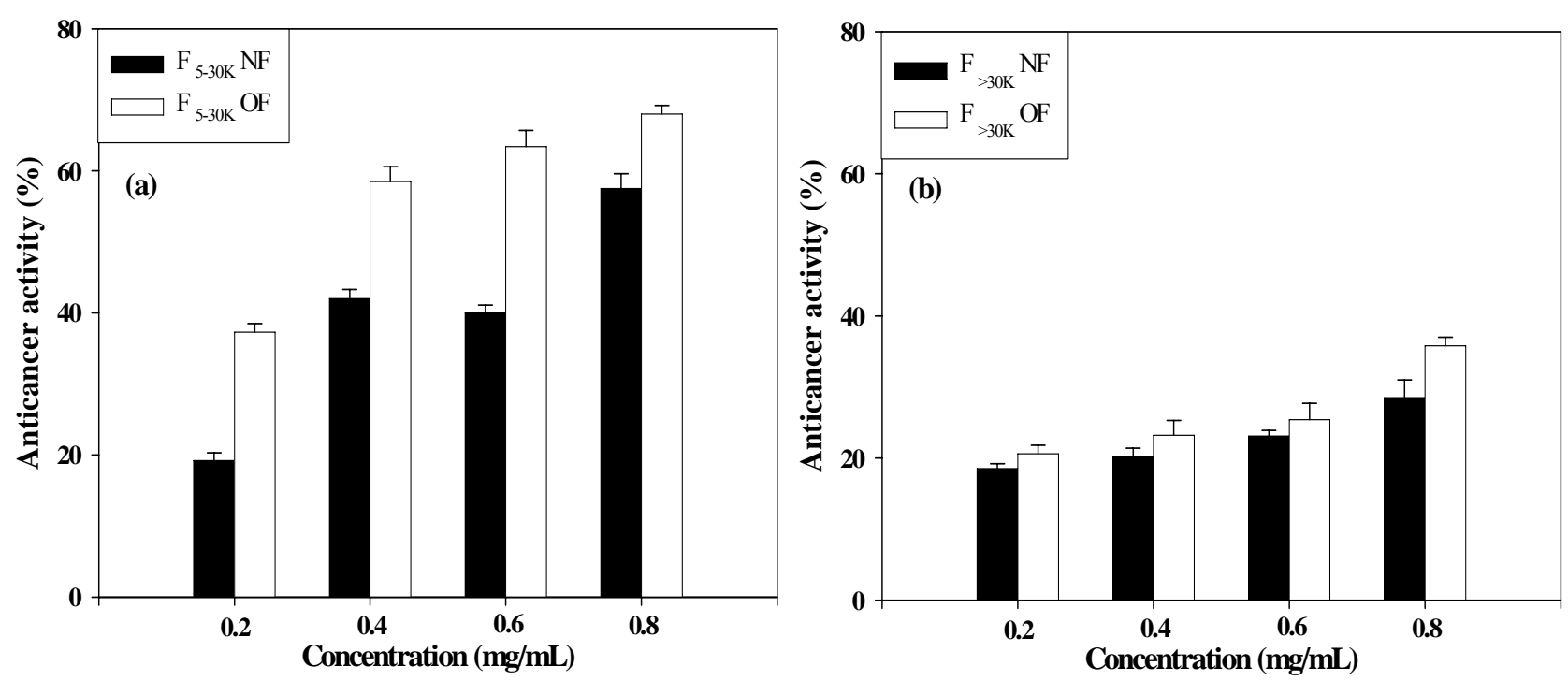

Our results suggest that the extent of sulfation can vary between fucoidan samples during the sulfation reaction, probably because of differences in their molecular structures such as molecular weight and conformation. In our preliminary study, when molecular weight $\left(\mathrm{M}_{\mathrm{w}}\right)$ was plotted against the radius of gyration $\left(\mathrm{R}_{\mathrm{g}}\right.$ ), based on the following relationship: $\mathrm{R}_{\mathrm{g}}=\mathrm{KM}_{\mathrm{w}}{ }^{\alpha}$ (sphere if $\alpha<0.3$; random coil if $0.3 \leq \alpha<0.5$; rod if $\alpha \geq 0.5$ ) [10], the native $F_{>30 \mathrm{~K}}$ fraction appeared to exist in a very compact conformation ( $\alpha=0.15$ ), possibly due to intra-molecular interactions, while the native $\mathrm{F}_{5-30 \mathrm{~K}}$ fraction appeared in a random coil conformation $(\alpha=0.42)$. As shown in Table 1 , after the sulfation reaction, the sulfate content of the $\mathrm{F}_{5-30 \mathrm{~K}}$ fraction increased to a greater extent than that of the $\mathrm{F}_{>30 \mathrm{~K}}$ fraction ( $21.3 \%$ vs. $9.5 \%$, respectively), suggesting that molecular conformation might affect the extent of sulfation in the fucoidan backbones during the sulfation reaction. The compact spherical conformation of the $\mathrm{F}_{>30 \mathrm{~K}}$ fraction likely indicates that the hydroxyl groups available for the substitution of sulfates were located inside the chains and might be involved in intramolecular interactions. Consequently, the compact conformation of the $\mathrm{F}_{>30 \mathrm{~K}}$ fraction would limit the degree of sulfation. However, for the $\mathrm{F}_{5-30 \mathrm{~K}}$ fraction, the fucoidan polymers were in a loose conformation, with more hydroxyl groups likely exposed and available for sulfate substitution. Therefore, the somewhat less compact conformation of the $\mathrm{F}_{5-30 \mathrm{~K}}$ fraction might result in the extensive sulfation of the fucan backbones and produce more 
highly sulfated fucoidan derivatives with improved anticancer activity. Despite the numerous studies on oversulfated fucoidans, the correlation between the extent of sulfation and the molecular conformation of fucoidans has not been reported. However, in the sulfation study of heparan polymers, it was suggested that a conformational arrangement of the polymeric chain would play an important role in the extent of sulfation because the exposure of the available hydroxyl groups would influence the degree of sulfate substitution [11].

\section{Experimental}

\subsection{Extraction, hydrolysis and fractionation of fucoidan}

The dried sporophyll of brown seaweed (Undaria pinnatifida), originating from the coast of Wando, Chunnam province, Korea, was purchased, milled using a blender, sieved $(<0.5 \mathrm{~mm})$ and then stored at $-20{ }^{\circ} \mathrm{C}$ until analysis. Native fucoidan was extracted from the dried biomass as previously reported [3]. Briefly, the dried biomass $(5 \mathrm{~g})$ was rehydrated in distilled water $(200 \mathrm{~mL})$ at $65{ }^{\circ} \mathrm{C}$ for 1

h. The soluble solid extract was mixed with $1 \% \mathrm{CaCl}_{2}$ and precipitated by centrifugation to remove alginic acid. Ethanol $(99 \%, 500 \mathrm{~mL})$ was added to the supernatant to obtain a final ethanol concentration of $70 \%(\mathrm{v} / \mathrm{v})$, and then the native fucoidan was filtered from the ethanol solution.

The native fucoidan was hydrolyzed according to the method of Nardella et al. [12] to produce low molecular weight fucoidans. The hydrolysis of fucoidan was carried out by dissolving the native fucoidan $(1.0 \mathrm{~g})$ and copper acetate monohydrate mixture $(0.08 \mathrm{~g}, 0.04 \mathrm{mM})$ in water $(10 \mathrm{~mL})$ at $60{ }^{\circ} \mathrm{C}$ while maintaining the $\mathrm{pH}$ at 7.5 by the addition of $2 \mathrm{M} \mathrm{NaOH}(0.2 \mathrm{~mL})$. Hydrogen peroxide solution $(90 \%, \mathrm{v} / \mathrm{v}, 0.5 \mathrm{~mL})$ was added to the fucoidan mixture at a flow rate of $12 \mathrm{~mL} / \mathrm{h}$, and hydrolysis by copper acetate monohydrate was performed for $5 \mathrm{hr}$ with constant mechanical stirring. The hydrolyzed fucoidan was fractionated using a Millipore Ultrafiltration System with 30 and $5 \mathrm{kDa}$ molecular weight cut-off membranes $\left(0.1 \mathrm{~m}^{2}\right.$, Millipore, USA). This produced three fucoidan fractions, $\mathrm{F}_{>30 \mathrm{~K}}\left(\mathrm{M}_{\mathrm{w}}\right.$ $>30 \mathrm{kDa}), \mathrm{F}_{5-30 \mathrm{~K}}\left(30 \mathrm{kDa}<\mathrm{M}_{\mathrm{w}}<5 \mathrm{kDa}\right)$ and $\mathrm{F}_{<5 \mathrm{~K}}\left(\mathrm{M}_{\mathrm{w}}<5 \mathrm{kDa}\right)$. Oversulfated fucoidan was obtained using the dimethylformamide (solvent) and sulfur trioxide-trimethylamine complex (sulfating agents) according to the method of Soeda et al. [4].

\subsection{Proximate composition and in vitro anticancer activity}

The sulfate content of fucoidan was determined by the $\mathrm{BaCl}_{2}$ gelatin method using $\mathrm{K}_{2} \mathrm{SO}_{4}$ as a standard after hydrolyzing the polysaccharide in $0.5 \mathrm{M} \mathrm{HCl}$ at $105^{\circ} \mathrm{C}$ for $5 \mathrm{hr}$ [13]. Total carbohydrate and total protein were determined by the phenol-sulfuric acid method using fucose as a standard [14] and by the Lowry method [15] using a DC Protein assay kit (Bio-Rad, Hercules, CA, USA), respectively. The FT-IR spectra ( $\mathrm{KBr}$ disc) were recorded using a Tensor 27 spectrophotometer (Bruker, Germany). The anticancer activity of fucoidans was determined using the sulforhodamine B (SRB) assay, as previously reported by Yang et al. [3].

\section{Conclusions}

This study describes the importance of molecular conformation on the sulfation of fucoidans, suggesting that the molecular conformation has a close relationship with the extent of sulfation in the 
fucan backbones during the sulfation reaction, with sulfate substitution occurring preferentially on fucoidans with a loose molecular conformation. In addition, the degree of sulfation appeared to influence the anticancer activity of fucoidans. It would therefore be beneficial to derive fucoidans with a less compact conformation as substrates for the extensive sulfate substitution and for the production of oversulfated fucoidans with greater anticancer activities.

\section{Acknowledgements}

This work was supported by both the Korea Research Foundation Grant funded by the Korean Government (MEST) (The Regional Core Research Program/Medical \& Bio-Materials Research Center) and the grant No. RTI05-01-02 from the Regional Technology Innovation Program of the Ministry of Knowledge Economy (MKE).

\section{References}

1. Chevolot, L.; Foucault, A.; Chaubet, F.; Kervarec, N.; Sinquin, C.; Fisher, A.M.; Boisson-Vidal, C. Further data on the structure of brown seaweed fucans: Relationships with anticoagulant activity. Carbohydr. Res. 1999, 319, 154-165.

2. Vieira, R.P.; Mourao, P.A. Occurrence of a unique fucose-branched chondroitin sulfate in the body wall of a sea cucumber. J. Biol. Chem. 1988, 263, 18176-18183.

3. Yang, C.; Chung, D.; Shin, I.S.; Lee, H.Y.; Kim, J.C.; Lee, Y.J.; You, S.G. Effects of molecular weight and hydrolysis conditions on anticancer activity of fucoidans from sporophyll of Undaria pinnatifida. Int. J. Biol. Macromol. 2008, 43, 433-437.

4. Soeda, S.; Sakaguchi, S.; Shimeno, H.; Nagamatsu, A. Fibrinolytic and anticoagulant activities of highly sulfated fucoidan. Biochem. Pharmacol. 1992, 43, 1853-1858.

5. Koyanagi, S.; Tanigawa, N.; Nakagawa, H.; Soeda, S.; Shimeno, H. Oversulfation of fucoidan enhances its anti-angiogenic and antitumor activities. Biochem. Pharmacol. 2003, 65, 173-179.

6. Haroun-Bouhedja, F.; Ellouali, M.; Sinquin, C.; Boisson-Vidal, C. Relationship between sulfate groups and biological activities of fucans. Thromb. Res. 2000, 100, 453-459.

7. Soeda, S.; Kozako, T.; Iwata, K.; Shimeno, H. Oversulfated fucoidan inhibits the basic fibroblast growth factor-induced tube formation by human umbilical vein endothelial cells: Its possible mechanism of action. Biochim. Biophys. Acta 2000, 1497, 127-134.

8. Qiu, X.D.; Amarasekara, A.; Doctor, V. Effect of oversulfation on the chemical and biological properties of fucoidan. Carbohydr. Polym. 2006, 63, 224-228.

9. Partankar, M.S.; Oehninger, S.; Barnett, T.; Williams, R.L.; Clark, G.F. A revised structure for fucoidan may explain some of its biological activities. J. Biol. Chem. 1993, 268, 21770-21776.

10. Roger, P.; Bello-Perez, L.A.; Colonna, P. Contribution of amylose and amylopectin to the light scattering behaviour of starches in aqueous solution. Polymer 1999, 40, 6897-6909.

11. Salmaso, N.; Castro, M.J.L.; Kovensky, J.; Fernandez, C.A. O-sulfation of 4-O-substituted derivatives of D-glucuronic acid. J. Arg. Chem. Soc. 2004, 92, 91-98.

12. Nardella, A.; Chaubeta, F.; Boisson-Vidala, C.; Blondina, C.; Durandb, P.; Jozefonvicza, J. Anticoagulant low molecular weight fucans produced by radical process and ion exchange 
chromatography of high molecular weight fucans extracted from the brown seaweed Ascophyllum nodosum. Carbohydr. Res. 1996, 289, 201-208.

13. Dodgson, K.S.; Price, R.G. A note on the determination of the ester sulfate content of sulfated polysaccharides. Biochem. J. 1962, 84, 106-110.

14. Dubois, M.; Gilles, K.A.; Hamilton, J.K.; Rebers, P.A.; Smith, F. Colorimetric method for determination of sugars and related substances. Anal. Chem. 1956, 28, 350-356.

15. Lowry, O.H.; Rosebrough, N.J.; Farr, A.L.; Randall, R.J. Protein measurement with the Folin phenol reagent. J. Biol. Chem. 1951, 193, 265-275.

Sample Availability: Oversulfated fucoidans from U. pinnatifida are available from the authors.

(C) 2010 by the authors; licensee MDPI, Basel, Switzerland. This article is an open access article distributed under the terms and conditions of the Creative Commons Attribution license (http://creativecommons.org/licenses/by/3.0/). 